\title{
Significados e Representações dos Números Racionais Abordados no Exame Nacional do Ensino Médio - ENEM
}

\author{
Meanings and Representations of Rational Numbers Addressed in the \\ National High School Exam - ENEM
}

\author{
Fernanda Andréa F. Silva \\ Mônica Maria Lins Santiago ** \\ Marcelo Câmara dos Santos ${ }^{* * *}$
}

\begin{abstract}
Resumo
Essa pesquisa se propõe a investigar quais são os significados e as representações dos números racionais que são contemplados no Exame Nacional do Ensino Médio - ENEM. Para tanto, tomamos como referência os estudos de Romanatto (1997) e Gomes (2010) e adotamos os seguintes significados para os números racionais: medida (parte-todo), quociente, razão, operador multiplicativo, probabilidade, um número na reta numérica e porcentagem. Para analisarmos os registros de representações dos números racionais que são contemplados no ENEM, utilizamos a Teoria das Representações Semióticas de Raymond Duval. Concluímos que os significados identificados nos itens relativos aos ENEM de 1998 a 2008 foram praticamente os mesmos identificados no período do novo ENEM. Nos itens referentes às provas de Matemática e suas Tecnologias dos ENEM de 2009 a 2011, o registro semiótico dos números racionais que mais pôde ser mobilizado durante suas resoluções foi o registro numérico fracionário.
\end{abstract}

Palavras-chave: Números Racionais. Significados. Representações. ENEM.

\begin{abstract}
This research proposes to investigate what are the meanings and the representations of the rational numbers that are contemplated in the National High School Exam - ENEM. Therefore, we take as reference the studies of Romanatto (1997) and Gomes (2010) and we adopted the following meanings for the rational numbers: measure

\footnotetext{
* Doutoranda do Programa Ensino das Ciências da Universidade Federal Rural de Pernambuco - UFRPE, Recife, Pernambuco, Brasil. Endereço para correspondência: Rua Jairo Marques Luz, n ${ }^{\circ}$ 03, Q. C, Loteamento Pôr do Sol, Tabuleiro do Martins, CEP 57081-596, Maceió, AL, Brasil. E-mail: fernandaandrea@ig.com.br.

${ }^{* *}$ Doutora em Psicologia Cognitiva pela Universidade Federal de Pernambuco - UFPE, Recife, Pernambuco, Brasil. Professora Adjunta do Departamento de Educação da Universidade Federal Rural de Pernambuco UFRPE, Recife, Pernambuco, Brasil. Endereço para correspondência: Rua São Salvador, n ${ }^{\circ} 105$, apto 704, Espinheiro, CEP: 52020-200, Recife, PE, Brasil. E-mail:monicamlins@gmail.com.

"Doutor em Ciências da Educação pela Université Paris-X. França. Professor do Programa de Pós-Graduação em Ensino das Ciências da Universidade Federal Rural de Pernambuco - UFRPE, Recife, Pernambuco, Brasil. Endereço para correspondência: Rua, Prof. Augusto Lins e Silva nº488/1902, Boa Viagem, 51030-030, Recife, PE, Brasil. E-mail: marcelocamararecife@gmail.com.
} 
(part-whole), quotient, reason, multiplicative operator, probability, a number in straight numerical, and percentages. To analyze the records of representations of the rational numbers that are contemplated in ENEM, we used the Theory of the Semiotics Representations by Raymond Duval, who considers that mathematical objects are not directly perceptible and that access to them is possible only through a system of representation. We concluded that, the meanings identified in the items relative to the 1998 to 2008 ENEM were virtually the same identified in the period of the new ENEM. In the items related to math tests and their technologies of the 2009 to 2011 ENEMs, the semiotic register of rational numbers that were most mobilized during its resolutions was the fractional numerical register.

Keywords: Rational numbers. Meanings. Representations. ENEM

\section{Introdução}

O ENEM é uma avaliação da aprendizagem com base nas competências e habilidades que o aluno deve desenvolver durante a educação básica. É pautado em uma concepção de ensino e aprendizagem contextualizada, problematizadora, que busca o desenvolvimento do sujeito voltado para a cidadania, como preconizam os documentos curriculares oficiais brasileiros (Parâmetros Curriculares Nacionais - PCN, Parâmetros Curriculares Nacionais para o Ensino Médio - PCNEM; e Diretrizes Curriculares Nacionais - DCN). Quando esse exame foi lançado, em 1998, era constituído de uma prova de conhecimentos gerais, contendo 63 itens de múltipla escolha e uma redação e se baseava em uma matriz de referência em que eram descritas as competências e habilidades a serem avaliadas. Em 2009, o ENEM foi reformulado, passando a chamar-se novo ENEM, e a ser constituído de 04 provas, Linguagens, Códigos e suas Tecnologias; Redação; Matemática e suas Tecnologias; e Ciências Humanas e suas Tecnologias. Cada prova, exceto a de redação, contém 45 itens de múltipla escolha. A matriz de referência desse exame passou a indicar os eixos cognitivos a serem avaliados, além das competências e habilidades, que também sofreram modificações.

Ramalho e Núñez (2011) apontam que

Os fundamentos dos referenciais nacionais do ensino médio, a partir do ENEM, colocam na pauta do Ministério da Educação um novo debate e, nesse sentido, esse exame passa a ter grande importância na função de fomentar a reforma, não apenas desta etapa de ensino, mas da educação básica como um todo (RAMALHO e NÚÑES, op.cit., p. 09).

Os autores acima citados afirmam, ainda, que conhecer a fundamentação desse exame é importante para uma reflexão acerca do ENEM e sua relação com o ensino escolar, de forma dialética e num duplo sentido. 
Pesquisas envolvendo o ensino-aprendizagem dos números racionais, como Catto (2000), Merlini (2005), Teixeira (2008), Santos (2005) têm demonstrado que esses números são de difícil compreensão para os alunos, devido à variedade de registros de representações e de significados envolvidos. Além disso, os alunos têm demonstrado dificuldades em compreender que algumas propriedades do conjunto dos números naturais só são válidas para esse domínio, favorecendo a criação de entraves à aprendizagem do conjunto dos números racionais e rupturas desse com o conjunto numérico dos naturais, como indicam os Parâmetros Curriculares Nacionais - PCN (BRASIL, 1997).

Dessa forma, com a finalidade de instigar as reflexões sobre o currículo acerca dos números racionais, esse estudo se propôs a responder a seguinte questão de pesquisa: Como são abordados os números racionais no Exame Nacional do Ensino Médio - ENEM, à luz de seus significados e das suas representações?

Isso nos leva a levantar alguns questionamentos, tais como:

- Quais os itens dos ENEM que mobilizam o conceito de números racionais, nos seus diferentes significados?

- Quais os significados dos números racionais abordados?

- Quais os registros semióticos presentes na estrutura do item ou que podem ser mobilizados durante a resolução do mesmo?

- Quais os tratamentos que podem ser realizados durante a resolução do item?

- Quais as conversões, que podem ocorrer entre os registros de representações semióticos?

Para realizar as análises necessárias neste trabalho, foi utilizado como referencial teórico a Teoria das Representações Semióticas de Duval (2003, 2009, 2011) e a classificação dos significados dos números racionais, proposta por Romanatto (1997) e Gomes (2010).

\section{Registros de Representação Semiótica}

É só analisarmos um pouco a história da Matemática para percebermos que o desenvolvimento da humanidade está atrelado à produção de sistemas semióticos, como os sistemas numéricos, pois "A matemática é o único domínio em que o progresso dos conhecimentos está estreitamente ligado à invenção de novos sistemas semióticos" (DUVAL, 2011, p.84). 
De acordo com Duval (2003), existem quatro tipos diferentes de registros em Matemática, discriminados no quadro 1.

\begin{tabular}{|c|c|c|}
\hline & REPRESENTAÇÃO DISCURSIVA & $\begin{array}{c}\text { REPRESENTAÇÃO NÃO } \\
\text { DISCURSIVA }\end{array}$ \\
\hline $\begin{array}{l}\text { REGISTROS } \\
\text { MULTIFUNCIONAIS; } \\
\text { Os tratamentos não são } \\
\text { algoritmizáveis }\end{array}$ & $\begin{array}{l}\text { Língua natural } \\
\text { Associações verbais (conceituais). } \\
\text { Forma de raciocinar: } \\
\text { - Argumentação a partir de observações, de } \\
\text { crenças, ...; }\end{array}$ & $\begin{array}{l}\text { Figuras geométricas planas ou em } \\
\text { perspectivas (configurações em } \\
\text { dimensão } 0,1,2 \text { ou } 3 \text { ) } \\
\text { - Apreensão operatória e não somente } \\
\text { perceptiva; }\end{array}$ \\
\hline $\begin{array}{l}\text { REGISTROS } \\
\text { MONOFUNCIONAIS: } \\
\text { Os tratamentos são } \\
\text { principalmente } \\
\text { algoritmos }\end{array}$ & $\begin{array}{l}\text { Sistemas de escritas: } \\
\text { - Numéricas (binária, decimal, } \\
\text { fracionária...); } \\
\text { - Algébricas; } \\
\text { - Simbólicas (línguas formais) }\end{array}$ & $\begin{array}{l}\text { Gráficos cartesianos } \\
\text { - Mudanças de sistema de } \\
\text { coordenadas; } \\
\text { - Interpolação, extrapolação }\end{array}$ \\
\hline
\end{tabular}

Quadro 1 - Classificação dos registros de representação semiótica em matemática Fonte: Duval (2003)

A importância da diversidade dos registros de representação para o funcionamento do pensamento é devida às diferenças de custo ou às limitações nas transformações internas a cada registro, podendo um registro, devido às suas características, permitir efetuar certas transformações de maneira mais econômica e mais eficiente do que outro registro.

Os registros discursivos permitem o desenvolvimento linear do pensamento, fundamentado na sucessão, para produzir, apreender ou organizar expressões, como na língua natural, que se constitui o primeiro registro de representação semiótica para o funcionamento do pensamento, apesar de, no ensino da Matemática, ser, em geral, reduzida à função de comunicação. Os registros não discursivos favorecem uma apreensão simultânea da sua organização dimensional (DUVAL, 2011).

Os registros monofuncionais são específicos da Matemática. Os registros multifuncionais são utilizados em outras áreas do conhecimento para as funções de: a) comunicação, ou seja, quando se tem que expressar algo; b) objetivação, quando se quer 
definir algo para si; e, muito raramente, como c) tratamento, quando se quer transformar os dados no interior de um registro. Entretanto, na Matemática, é o contrário que se produz, pois a língua materna (registro multifuncional) é utilizada inicialmente para a função de tratamento (ibid).

No nosso campo de pesquisa, os números racionais, o registro multifuncional na representação discursiva compreende os registros dos números racionais na língua natural, como um doze avos, cinco décimos ou vinte por cento. Esse registro está associado diretamente ao vocabulário que é intrínseco a cada cultura e permite ao sujeito, que se utiliza adequadamente dele, expressar-se ou comunicar-se corretamente.

O registro multifuncional na representação não discursiva é composto pelo registro figural, que envolve as situações de partições de grandezas contínuas e discretas.

$\mathrm{O}$ registro monofuncional discursivo compreende o registro simbólico numérico e algébrico dos números racionais. No registro simbólico numérico está a forma fracionária que pode assumir os significados parte-todo, razão, quociente, operador multiplicativo e probabilidade, de acordo com a classificação que adotamos. Nesse domínio estão, também, os números racionais na forma decimal exata, quando têm um número finito de casas decimais, e na forma decimal não exata, quando temos infinitas casas decimais que se repetem segundo um período. Ainda no registro simbólico numérico, temos a potência de dez e os percentuais, que estão presentes em situações que envolvem porcentagem, outro significado que adotamos para os números racionais. No registro simbólico algébrico estão as formas algébricas fracionária, decimal e potência de dez, necessárias em situações que requerem generalizações dos números racionais.

Os registros monofuncionais não discursivos compreendem os registros gráficos, em que os números racionais correspondem a pontos na reta numérica.

Esses múltiplos registros de representações do número racional fazem com que, muitas vezes, os alunos sintam dificuldades em identificar diferentes registros de representações como sendo de um mesmo número racional (MARANHÃO e IGLIORI, 2003).

Segundo Duval (2011), a especificidade da atividade matemática se encontra em mobilizar simultaneamente ao menos dois desses registros de representação ou na possibilidade de mudar de registro sempre que for conveniente.

Um registro de representação será considerado como tal, por um sujeito, ou seja, não será confundido com o objeto representado, lhe dando acesso a esse objeto, quando o sujeito 
dispor de ao menos dois sistemas semióticos diferentes para produzir esse registro e converter naturalmente de um sistema semiótico a outro, mesmo sem se dar conta dos registros produzidos (DUVAL, 2009).

Entretanto, Duval (ibid) afirma que não basta conhecer regras de correspondência entre dois sistemas semióticos para que ambos sejam mobilizados e utilizados de forma coordenada, é necessária a colocação em correspondência das unidades de sentido que são próprias de cada registro de representação.

Para isso, Duval (2011) distingue dois tipos de transformações de representações semióticas. Quando elas ocorrem no interior de um registro são chamadas, de 'tratamentos'. Aquelas que mudam de registro de representação, conservando o mesmo objeto analisado são chamadas de 'conversões'.

Os tratamentos são transformações que dependem do tipo de registro de representação semiótica no qual se está trabalhando, pois obedecem ao um modo próprio de funcionamento deste e requerem operações cognitivas que são particulares para cada registro de representação. Para exemplificar, temos as seguintes somas: $3+2 ; 0,3+0,2$ e $\frac{1}{3}+\frac{1}{2}$. Ao somar esses valores numéricos estaremos transformando-os, utilizando para isso, as regras de funcionamento de cada registro numérico (inteiro, decimal e fracionário) e que exigem custos cognitivos diferentes.

As conversões provocam uma mudança de registro de representação que não se prende apenas ao conteúdo da representação, mas às operações semióticas que irão transformar o conteúdo dessa representação.

Portanto, essas transformações (as conversões), não se reduzem apenas ao conhecimento dos códigos necessários a uma transformação entre registros, mas exigem uma

[...] necessária articulação entre as variáveis cognitivas que são específicas do funcionamento de cada um dos dois registros. Pois são essas variáveis que permitem determinar quais as unidades de significado pertinente, que devem ser levadas em consideração, em cada um dos dois registros (DUVAL, 2003, p. 17)

Estas considerações levam o aluno a estabelecer relações e analisar aspectos diferentes de um mesmo objeto.

Entretanto, a conversão é uma operação que não é cognitivamente reversível. Um sujeito que converte um registro de representação em outro não converterá, necessariamente no sentido inverso, pois 


\begin{abstract}
A conversão direta e a conversão inversa são duas tarefas cognitivas tão diferentes quanto subir ou descer um caminho íngreme na montanha. Em outras palavras, para que haja coordenação sinérgica de vários registros, é preciso ser capaz de converter as representações nos dois sentidos e não em um único (DUVAL, 2011, p.118)
\end{abstract}

Entre os números racionais, Duval (2009) afirma que pesquisas têm identificado que alguns alunos, mesmo sabendo efetuar uma adição de números na forma fracionária e decimal, chegam ao seconde ${ }^{1}$ sem saberem converter um número na forma decimal em um número na forma fracionária e reciprocamente. É preciso discernir a significação operatória ligada ao significante e o número representado. Dessa forma, a significação operatória não será a mesma para 0,$25 ; \frac{1}{4}$ e $25 \times 10^{-2}$, pois os tratamentos que permitem efetuar as adições são diferentes $\left(0,25+0,25=0,5 ; \frac{1}{4}+\frac{1}{4}=\frac{1}{2} ; 25 \times 10^{-2} \times 25 \times 10^{-2}=50 \times 10^{-2}\right)$.

Portanto, investigar os registros mobilizados, as conversões e os tratamentos que podem ser realizados nas resoluções dos itens do Exame Nacional do Ensino Médio pode favorecer a uma análise cognitiva do que esse exame deve estar requerendo dos sujeitos, quanto ao campo dos números racionais.

\title{
3 Percurso metodológico
}

Essa pesquisa procurou investigar como são abordados os números racionais no Exame Nacional do Ensino Médio - ENEM, à luz de seus significados e das suas representações. Para isso a análise foi dividida em duas etapas:

Etapa I - Análise das provas de conhecimentos gerais dos ENEM de 1998 a 2008 e das provas de Matemática e suas tecnologias dos ENEM de 2009 a 2011, no sentido de identificar os itens que contemplavam o conceito de números racionais nos seus diferentes significados.

Etapa II - Análise dos itens identificados na etapa I, referente às provas de Matemática e suas tecnologias dos ENEM de 2009 a 2011, visando identificar os registros de representações contidos na estrutura do item, os tratamentos e as conversões que podem ser mobilizados durante a resolução do item.

Os itens das provas de Matemática e suas tecnologias dos ENEM de 2009 a 2011 (novo ENEM) foram analisados na etapa II de acordo com o roteiro abaixo:

\footnotetext{
${ }^{1}$ Corresponde ao primeiro ano do Ensino Médio no Brasil.
} 
1) estratégia esperada de resolução, incluindo tratamentos e conversões (quando houver);

2) outra(s) estratégia(s) de resolução (quando for pertinente);

3) análise do suporte (quando houver);

4) estrutura do item, quanto aos registros de representações envolvidos;

5) alguns comentários referentes às habilidades necessárias à resolução do item e outros conceitos exigidos (quando for pertinente);

\subsection{Análise da etapa I: itens que contemplam o conceito de números racionais nos ENEM de 1998 a 2011}

Da análise das provas de conhecimentos gerais dos ENEM de 1998 a 2008 foram identificados 41 itens e das provas de Matemática e suas tecnologias dos ENEM de 2009 a 2011, 29 itens, totalizando 70 itens que contemplam o conceito de números racionais, nos seus diferentes significados, apresentados no gráfico 1, por ano de aplicação do ENEM.

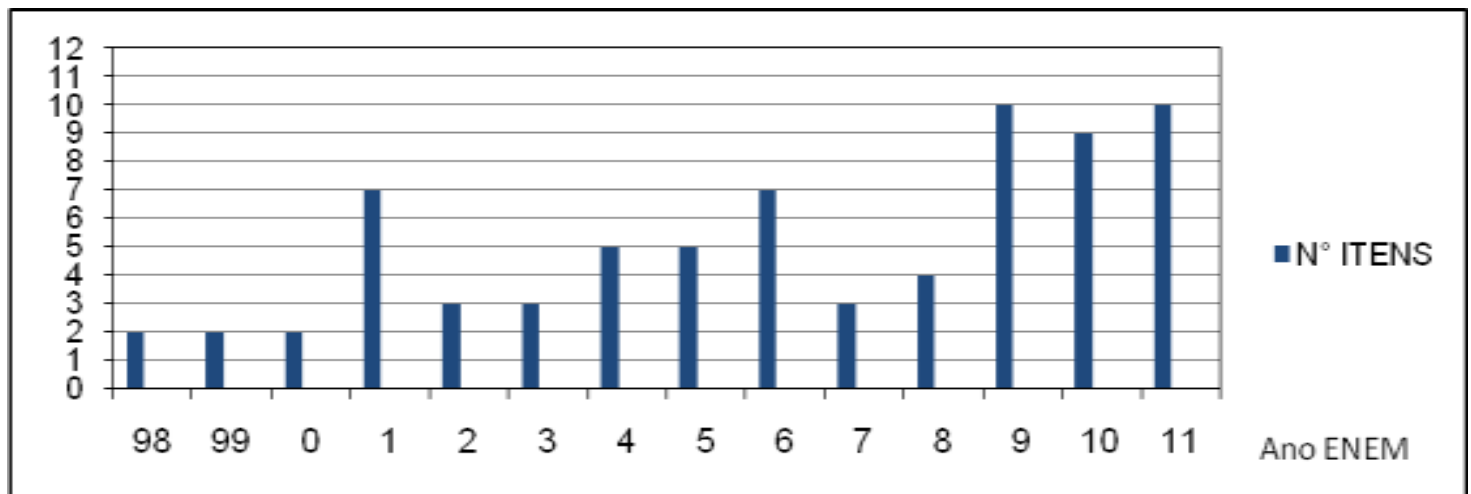

Gráfico1- Quantidade de itens por prova do ENEM que contemplam algum tipo de significado ou representação do número racional

Fonte: (Silva, 2013)

As provas de conhecimentos gerais dos ENEM de 1998 à 2008 apresentaram uma média de 3,5 itens, por prova, que contemplam algum tipo de significado e representação dos números racionais, o que corresponde a aproximadamente 5,6\% do total de 63 itens que cada prova continha.

Entre as provas de Matemática e suas tecnologias do novo ENEM, que corresponde ao período de 2009 à 2011, foram encontrados, em média, 9,6 itens por prova que abordam algum tipo de significado e representação dos números racionais, correspondendo a 
aproximadamente $21 \%$ do total de 45 itens da prova. Esse resultado pode indicar a necessidade e a importância do aluno saber mobilizar o conceito dos números racionais na resolução dos itens do ENEM.

O crescimento no número de itens por prova que abordam o conceito dos números racionais, no novo ENEM se comparado com os ENEM de 1998 a 2008, pode ter ocorrido pelo fato de a nova versão desse exame constar de uma prova de Matemática e suas Tecnologias com 45 itens, enquanto que a versão antiga constava de 63 itens envolvendo não só Matemática e suas Tecnologias, como também as áreas de ciências da natureza e ciências humanas. Além disso, o novo ENEM assume um outro caráter que é o de servir como processo seletivo para o Ensino Superior, o que pode estar indicando que o crescimento no número de itens que envolve o conceito de números racionais se deve à importância desse conhecimento não só no cotidiano das pessoas, quanto na vida acadêmica, e a consequente necessidade de ser avaliado entre os concluintes e egressos do Ensino Médio.

\subsection{Significados dos números racionais contemplados nos ENEM de 1998 à 2011}

Nas provas de conhecimentos gerais dos ENEM de 1998 a 2008 foram identificados 41 itens que mobilizam o conceito de números racionais nos significados operador multiplicativo, parte-todo, razão, porcentagem e probabilidade. Alguns desses itens envolvem mais de um significado do número racional, como pode ser visto no quadro 2.

\begin{tabular}{|c|c|c|c|c|c|c|c|c|c|}
\hline ENEM & $\begin{array}{c}\mathbf{n}^{\circ} \\
\text { itens }\end{array}$ & $\begin{array}{c}\text { Op. } \\
\text { Multip. }\end{array}$ & Parte-todo & razão & Quoc & Porcent & Probab & $\begin{array}{c}\text { Núm. } \\
\text { na } \\
\text { reta }\end{array}$ & $\begin{array}{c}\text { Mais de } \\
\text { um signif. }\end{array}$ \\
\hline 1998 & 02 & - & - & - & - & 02 & - & - & - \\
\hline 1999 & 02 & - & - & 02 & - & - & - & - & - \\
\hline 2000 & 02 & - & - & 02 & - & 02 & - & - & 02 \\
\hline 2001 & 07 & - & 01 & 03 & - & 06 & - & - & 03 \\
\hline 2002 & 03 & - & - & 01 & - & 02 & - & - & - \\
\hline 2003 & 03 & - & - & 01 & - & 02 & - & - & - \\
\hline 2004 & 05 & 01 & 03 & 01 & - & 02 & - & - & 02 \\
\hline 2005 & 05 & - & - & 01 & - & 02 & 02 & - & - \\
\hline 2006 & 07 & - & - & 02 & - & 05 & 01 & - & 01 \\
\hline 2007 & 03 & - & - & 01 & - & 01 & 02 & - & 01 \\
\hline 2008 & 02 & - & - & - & - & 01 & 01 & - & 01 \\
\hline Total & $\mathbf{4 1}$ & $\mathbf{0 1}$ & $\mathbf{0 4}$ & $\mathbf{1 4}$ & - & $\mathbf{2 5}$ & $\mathbf{0 6}$ & - & $\mathbf{1 0}$ \\
\hline
\end{tabular}

Quadro 2 - Significados dos números racionais identificados nos itens dos ENEM de 1998 a 2008 Fonte: (Silva, 2013) 
Desses itens identificados como mobilizadores de algum tipo de significado do número racional, $61 \%$ abordam o significado porcentagem, $34,1 \%$ razão, 14,6\% probabilidade, 9,7\% parte-todo e não conseguimos identificar nenhum item que envolvesse os significados quociente e número na reta numérica. Esses resultados podem ser justificados devido ao fato de o ENEM priorizar situações que envolvam contextos econômicos e sociais, ou seja, relacionados à cidadania, nos quais os significados porcentagem, razão e probabilidade podem se fazer mais frequentes.

O quantitativo de itens que envolvem os significados dos números racionais contemplados nos itens identificados nas provas de matemática e suas tecnologias dos ENEM de 2009 a 2011 estão descritos no quadro 3.

\begin{tabular}{|c|c|c|c|c|c|c|c|c|c|}
\hline ENEM & $\begin{array}{c}\mathbf{n}^{\circ} \\
\text { itens }\end{array}$ & $\begin{array}{c}\text { Op. } \\
\text { Multip. }\end{array}$ & Parte-todo & razão & Quoc & Porcent & Probab & $\begin{array}{c}\text { Núm. } \\
\text { na reta }\end{array}$ & $\begin{array}{c}\text { Mais de } \\
\text { um } \\
\text { signif. }\end{array}$ \\
\hline $\mathbf{2 0 0 9}$ & 10 & - & 01 & 03 & - & 06 & 01 & - & 01 \\
\hline $\mathbf{2 0 1 0}$ & 09 & - & 01 & 01 & - & 07 & 01 & - & 01 \\
\hline $\mathbf{2 0 1 1}$ & 10 & - & 01 & 03 & - & 03 & 03 & - & - \\
\hline Total & $\mathbf{2 9}$ & & $\mathbf{0 3}$ & $\mathbf{0 7}$ & - & $\mathbf{1 6}$ & $\mathbf{0 5}$ & - & $\mathbf{0 2}$ \\
\hline
\end{tabular}

Quadro 3 - Significados dos números racionais identificados nos itens dos ENEM de 2009 a 2011 Fonte: (Silva, 2013)

Se compararmos os dados do quadro 3, referentes aos itens identificados do novo ENEM que mobilizam o conceito de números racionais, com os do quadro 2, que apresenta os significados mobilizados pelos itens identificados dos ENEM de 1998 a 2008 verificamos que há uma tendência desses exames em priorizar o significado porcentagem, seguido pelo significado razão, probabilidade e parte-todo.

\subsection{Análise da etapa II: síntese da análise dos ENEM de 2009 a 2011}


Dos 29 itens analisados dos ENEM de 2009 a 2011, verificamos que foram os seguintes significados mobilizados: parte-todo, razão, porcentagem e probabilidade, de acordo com o gráfico 4 .

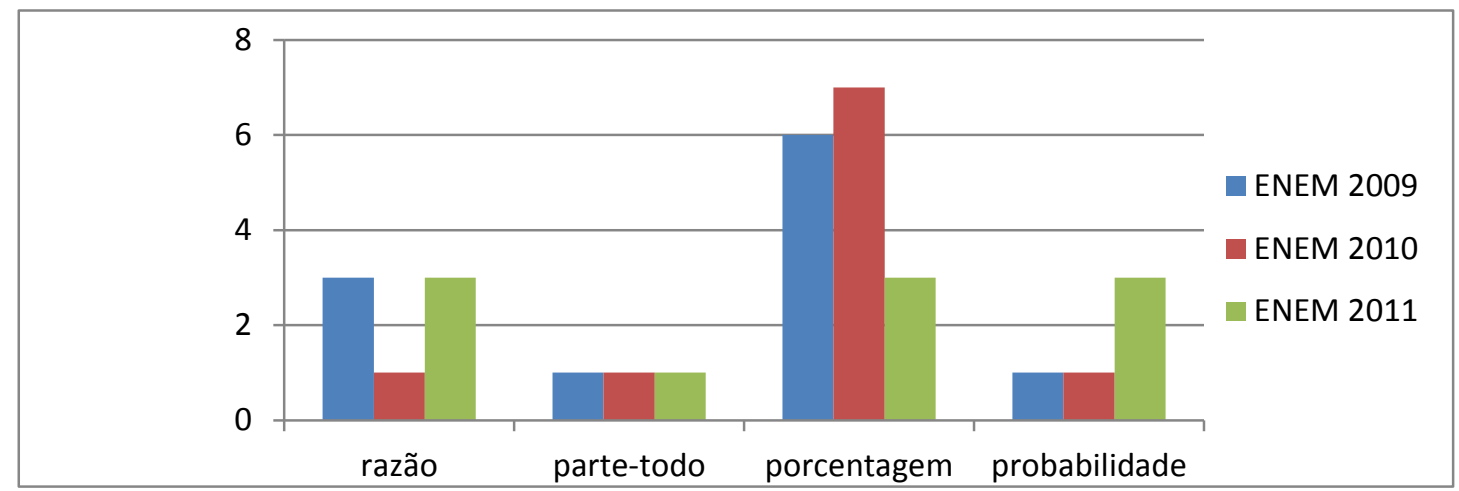

Gráfico 4 - Significados dos números racionais abordados nos itens das provas de matemática e suas tecnologias dos ENEM 2009 a 2011

Fonte: (Silva, 2013)

O significado parte-todo correspondeu a $10,3 \%$ do total de itens analisados nas provas de Matemática e suas Tecnologias dos ENEM de 2009 a 2011, tendo apresentado uma maior uniformidade, pois foi mobilizado em apenas um item a cada prova. O significado probabilidade foi abordado em $17,2 \%$ do total de itens, tendo sofrido um acréscimo no número de itens mobilizados no ENEM 2011, em relação aos ENEM 2009 e 2010, passando de um item por prova para três itens.

O significado razão foi mobilizado em 24,1\% dos itens analisados dos ENEM de 2009 a 2011, tendo sofrido uma redução no número de itens mobilizados no ENEM 2010 (apenas1 item), em relação ao ENEM 2009 (três itens), mas voltou a ser mobilizado em três itens no ENEM 2011. O significado porcentagem foi o mais abordado, correspondendo a $58,6 \%$ dos itens analisados dos ENEM de 2009 a 2011, tendo sofrido uma redução nos itens que envolviam esse significado no ENEM 2011, o qual apresentou uma uniformidade nos significados razão, porcentagem e probabilidade.

Esses resultados nos revelam que há uma tendência, nesse exame, em abordar os significados, razão, porcentagem, probabilidade e parte-todo, em detrimento dos outros significados, número na reta numérica, quociente e operador multiplicativo. Acreditamos que isso se deve pelo fato de algumas habilidades e competências que o ENEM se propõe avaliar mobilizarem os significados que foram privilegiados nesse exame. Quanto à uniformidade 
entre os significados, razão, porcentagem e probabilidade demonstrada no ENEM 2011, não podemos afirmar se representa uma mudança na forma desses significados serem abordados pelo ENEM, visto que seria necessário, ao menos, uma análise da versão 2012 para podermos indicar algo nesse sentido.

Os registros de representação semiótica dos números racionais existentes na estrutura (enunciado, suporte, comando e alternativas de respostas) dos 29 itens analisados dos ENEM 2009 (10 itens), 2010 (09 itens) e 2011(10 itens) foram o numérico decimal, potência de dez, numérico razão, numérico fracionário, numérico percentual e figural, como representados no gráfico 5.

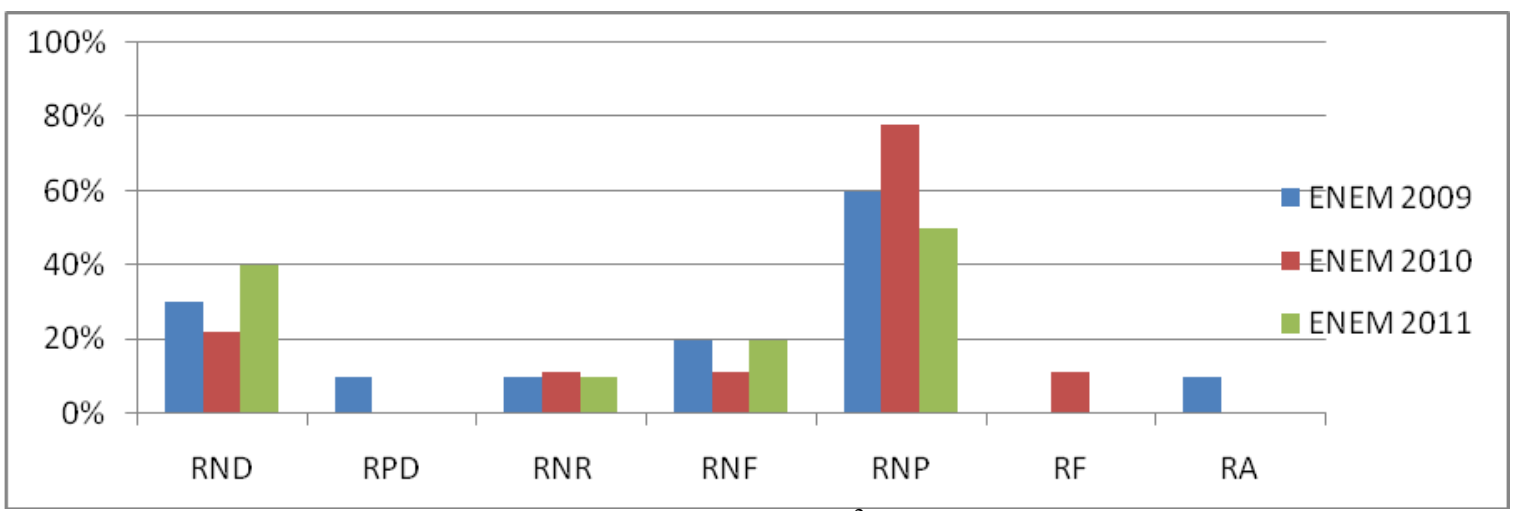

Gráfico 5 - Percentuais de registros dos números racionais ${ }^{2}$ existentes na estrutura dos itens de acordo com o ano do ENEM

Fonte: (Silva, 2013)

O registro numérico percentual foi o que mais esteve presente na estrutura dos itens dos ENEM 2009 a 2011 (62,6\%, em média), embora no ENEM 2011, o significado porcentagem não tendo sido o mais abordado. O registro potência de dez só esteve presente no ENEM 2009 e o figural (dos números racionais), apenas no ENEM 2010, ambos com uma única questão.

O gráfico 6 apresenta os registros de representação semiótica presentes na estrutura dos 29 itens dos ENEM 2009 a 2011, de acordo com o significado envolvido.

\footnotetext{
${ }^{2}$ Utilizamos as seguintes abreviações para os registros: RNR- registro numérico razão; RNF - registro numérico fracionário; RND- registro numérico decimal; RNP - registro numérico percentual; RA - registro algébrico; RLM- registro da língua materna; RF- registro figural; RNI- registro numérico inteiro; RD- registro em diagrama.
} 


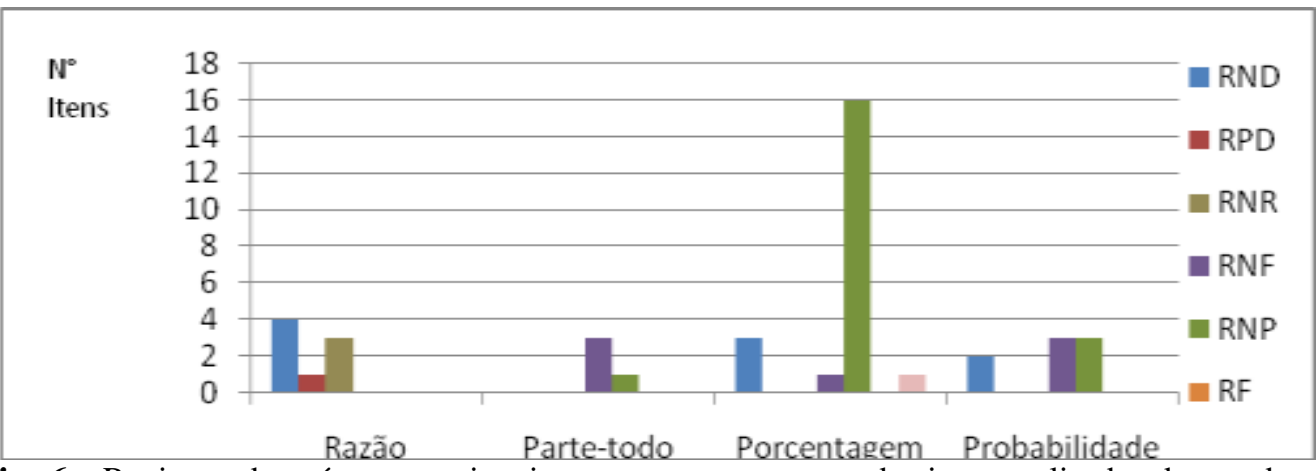

Gráfico 6 - Registros dos números racionais presentes na estrutura dos itens analisados de acordo com o significado envolvido

Fonte: (Silva, 2013)

O registro numérico percentual se mostra presente também na estrutura dos itens que envolvem os significados probabilidade e parte-todo, isso pode justificar o fato de no ENEM 2011 esse registro continuar sendo o que mais apareceu na estrutura dos itens, apesar da redução de itens que envolveram o significado porcentagem, pois nesse mesmo exame verificamos um acréscimo no número de itens que abordaram o significado probabilidade.

Os registros de representação dos números racionais que podem ser mobilizados (transformados por meio de tratamentos ou conversões) durante a análise das possíveis estratégias de resolução dos itens dos ENEM 2009 a 2011 foram o numérico fracionário, algébrico, potência de dez, numérico decimal, numérico razão, numérico percentual e figural. Esses registros estão representados no gráfico 7, de acordo com o ano do ENEM.

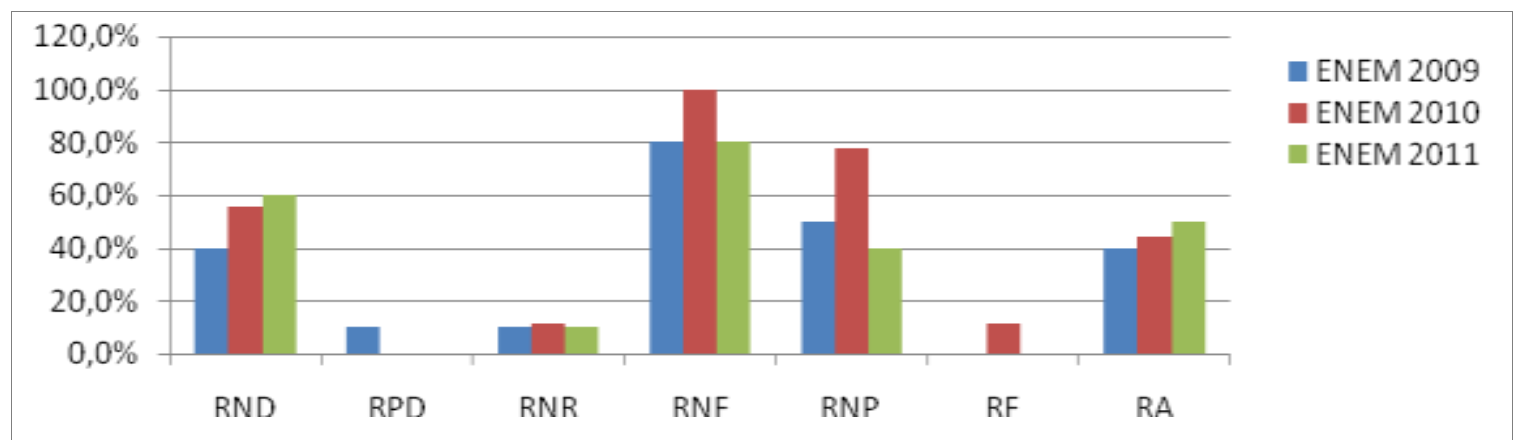

Gráfico 7 - Percentuais dos registros dos números racionais que podem ser mobilizados nos itens de acordo com o ano do ENEM

Fonte: (Silva, 2013)

O registro numérico fracionário foi o que mais pôde ser mobilizado nas resoluções dos itens analisados dos ENEM 2009 a 2011. O registro potência de dez só pôde ser mobilizado no ENEM 2009 e o figural, no ENEM 2010. 
Comparando os registros dos números racionais existentes na estrutura (enunciado, suporte, comando e alternativas de respostas) dos itens analisados dos ENEM 2009 a 2011 com os que podem ser mobilizados durante a resolução desses, verificamos que, apesar de o registro numérico porcentagem ser o que mais esteve presente na estrutura dos itens, o registro que mais pôde ser mobilizado nas estratégias de resolução desses, ou seja, transformado através de tratamentos e conversões, foi o numérico fracionário.

O gráfico 8 apresenta os registros de representação dos números racionais que podem ser mobilizados na resolução dos vinte e nove itens, de acordo com o significado em que foi abordado.

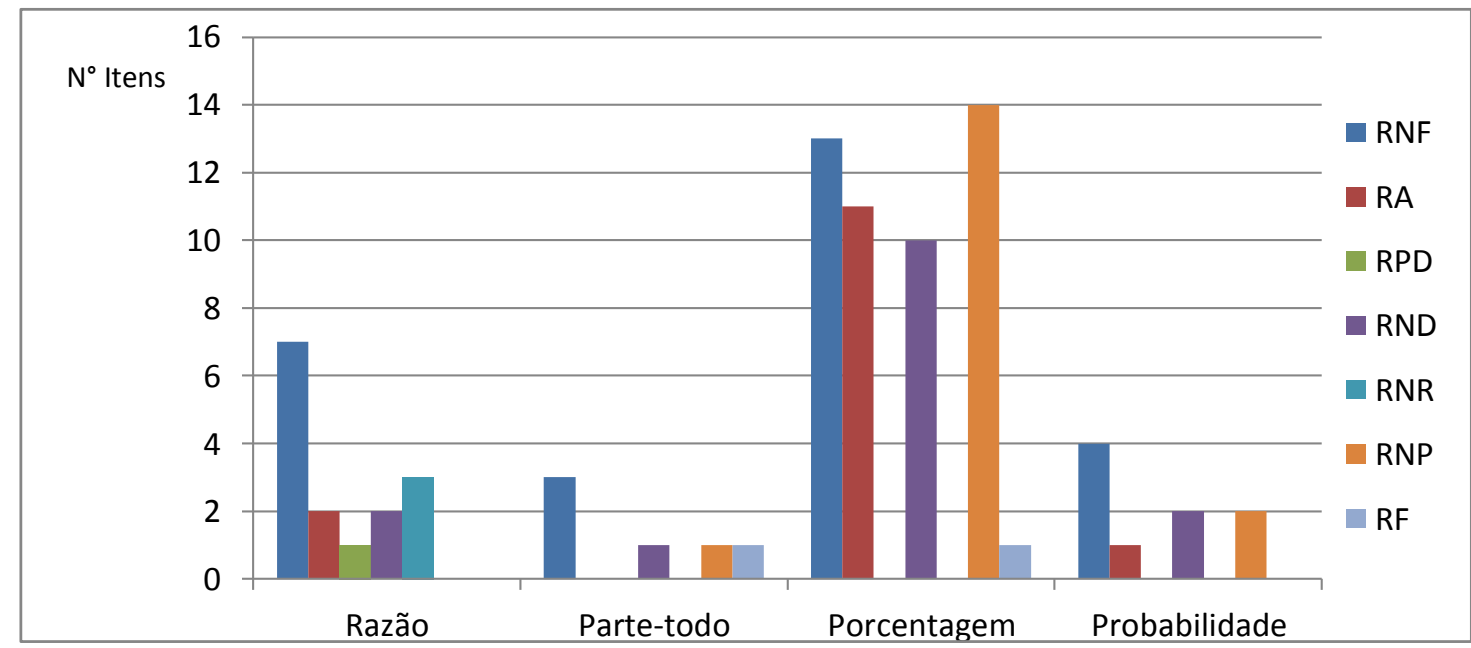

Gráfico 8 - Registros dos números racionais mobilizados nas resoluções dos itens de acordo com o significado envolvido

Fonte: (Silva, 2013)

Considerando os 7 itens que envolveram o significado razão, 3 itens que mobilizaram o significado parte-todo, 16 itens que abordaram o significado porcentagem e 5 itens que mobilizaram o significado probabilidade, entre o total de itens (29) analisados dos ENEM 2009 a 2011, o registro numérico fracionário foi o que pôde ser mais mobilizado nas estratégias de resolução desses, ou seja, que envolveu os significados, razão (todos os itens), parte-todo (todos os itens), e probabilidade (4 dos 5 itens); e o segundo mais mobilizado nos itens que envolveram o significado porcentagem (12 dos 16 itens). Nesse significado o registro mais mobilizado foi o numérico percentual (14 itens). O registro numérico percentual é mobilizado também nos itens que envolvem o significado probabilidade e parte-todo.

O registro algébrico é bastante mobilizado no significado porcentagem (11 dos 16 itens), nas estratégias que envolvem o raciocínio proporcional e só não foi utilizado nos itens que envolvem o significado parte-todo. O registro potência de dez e o numérico razão foram 
mobilizados apenas no significado razão, o qual não apresentou itens que mobilizassem o registro percentual. $\mathrm{O}$ registro figural foi mobilizado apenas nos significados parte-todo e porcentagem.

As conversões mobilizadas entre a língua materna e os registros dos números racionais tiveram como registros de chegada: numérico decimal, numérico fracionário, numérico percentual e algébrico. Esses registros de chegada estão descritos no gráfico 9, de acordo com o significado que o item aborda.

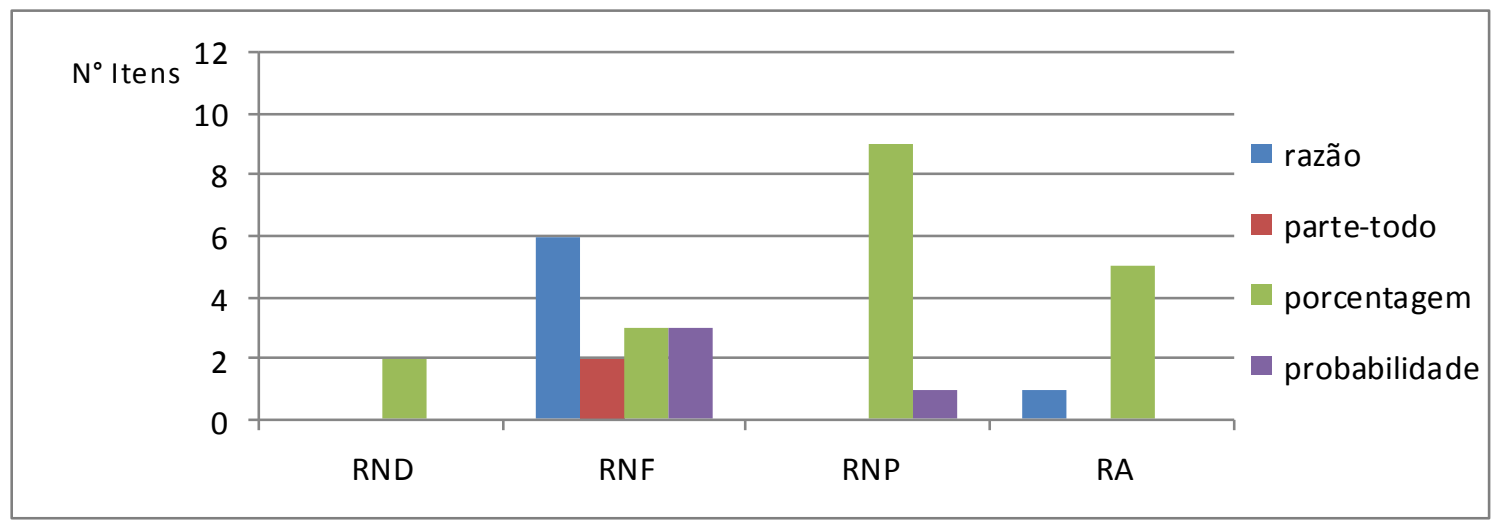

Gráfico 9 - Conversões mobilizadas entre o registro da língua materna e os registros dos números racionais de acordo com o significado envolvido

Fonte: (Silva,2013)

Todos os significados tiveram itens em que podem ocorrer as conversões entre a língua materna e o registro numérico fracionário. As conversões cujo registro de chegada foi o numérico decimal só ocorreram nos itens que envolviam o significado porcentagem. Aquelas que tinham como registro de chegada o numérico percentual ocorreram, em sua maioria ( 9 de 10 itens), nos itens que mobilizaram o significado porcentagem; e as que tiveram como registro de chegada o algébrico ocorreram em itens que envolveram o significado porcentagem (5 itens) e o significado razão (1item).

O quadro 4 apresenta as conversões que têm como registro de partida a língua materna e como registro de chegada os registros dos números racionais, de acordo com os itens em que foram mobilizadas nos ENEM 2009 a 2011.

\begin{tabular}{|c|c|c|c|c|}
\hline $\begin{array}{c}\text { Registro de } \\
\text { Chegada }\end{array}$ & $\begin{array}{c}\mathbf{N}^{\circ} \text { Itens do } \\
\text { ENEM 2009 }\end{array}$ & $\begin{array}{c}\mathbf{N}^{\circ} \text { itens do } \\
\text { ENEM 2010 }\end{array}$ & $\begin{array}{c}\mathbf{N}^{\circ} \text { itens do } \\
\text { ENEM 2011 }\end{array}$ & $\begin{array}{c}\mathbf{N}^{\circ} \text { total de itens } \\
(\%)\end{array}$ \\
& $(\%)$ & $(\%)$ & $(\%)$ & \\
\hline
\end{tabular}




\begin{tabular}{|c|c|c|c|c|}
\hline RA & 40 & 11,1 & 10 & 20,7 \\
\hline RNP & 20 & 55,5 & 30 & 34,5 \\
\hline RNF & 30 & 55,5 & 60 & 48,3 \\
\hline RND & 0 & 0 & 20 & 6,9 \\
\hline
\end{tabular}

Quadro 4 - Percentuais dos itens que envolvem as conversões entre o registro da língua materna e os registros dos números racionais dos ENEM 2009 a 2011

Fonte: (Silva, 2013)

As conversões entre a língua materna e os registros dos números racionais que podem ser mais mobilizadas, no ENEM 2011 (60\%) e no total de itens analisados (48,3\%), são aquelas que têm como registro de chegada o numérico fracionário, talvez devido ao fato de o ENEM 2011 manter uma uniformidade entre os significados, probabilidade, porcentagem e razão, e o registro numérico fracionário ter sido o mais presente nas estratégias de resolução dos significados abordados nos itens, de acordo com o gráfico 9.

No ENEM 2009, esse tipo de conversão envolveu, em maior número (40\%), aquelas que tiveram como registro de chegada o algébrico. No ENEM 2010, esse tipo de conversão ocorreu na mesma proporção para as que tiveram como registro de chegada o numérico percentual e fracionário, o que pode ter sido devido ao fato de esse exame abordar um número superior de itens que envolveram o significado porcentagem.

As conversões entre os registros dos números racionais estão descritas no gráfico 10 , de acordo com os significados envolvidos.

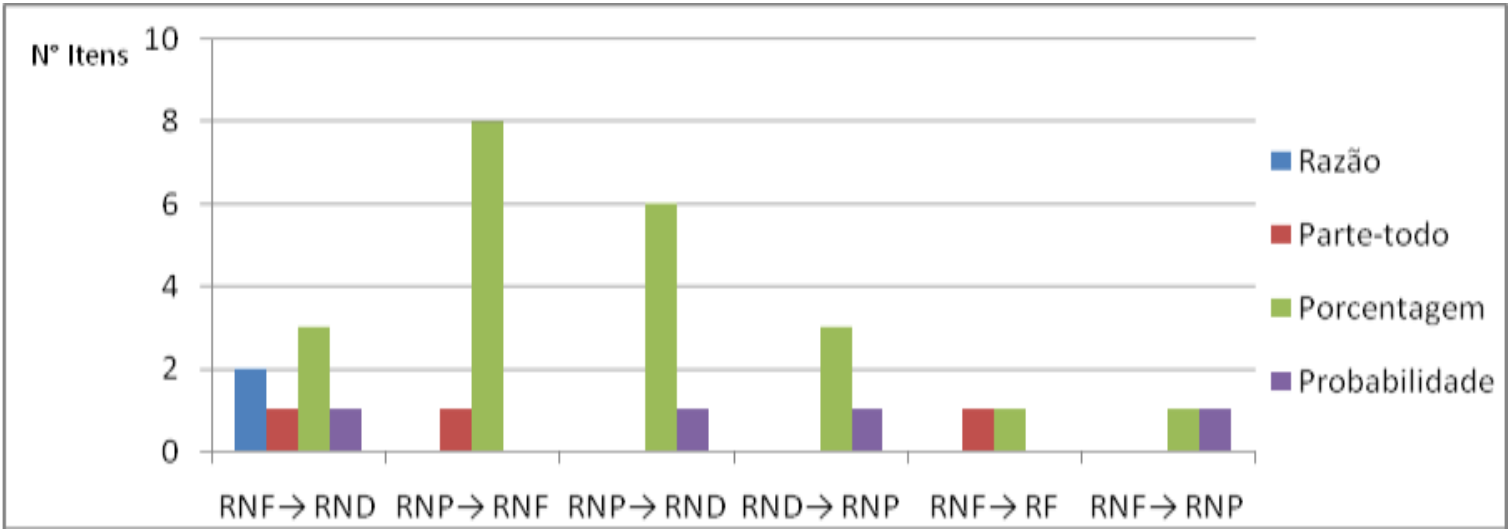

Gráfico 10 - Conversões entre os registros dos números racionais, de acordo com o significado envolvido Fonte: (Silva, 2013)

O significado porcentagem mobilizou todas as conversões ocorridas entre os tipos de registros dos números racionais. O significado razão envolveu apenas conversões entre os 
números racionais que tinham como registro de partida o numérico fracionário e como registro de chegada o numérico decimal.

O quadro 5 apresenta as conversões que têm como registros de partida e de chegada os números racionais e que podem ser mobilizadas nas estratégias de resolução de $62 \%$ (18 itens) do total dos itens analisados dos ENEM de 2009 a 2011.

\begin{tabular}{|c|c|c|c|c|c|}
\hline $\begin{array}{c}\text { Registro de } \\
\text { Partida }\end{array}$ & $\begin{array}{c}\text { Registro de } \\
\text { Chegada }\end{array}$ & $\begin{array}{c}\text { Percentual } \\
\text { de Itens do } \\
\text { ENEM } \\
\mathbf{2 0 0 9}(\boldsymbol{\%})\end{array}$ & $\begin{array}{c}\text { Percentual } \\
\text { de itens do } \\
\text { ENEM } \\
\mathbf{2 0 1 0}(\boldsymbol{\%})\end{array}$ & $\begin{array}{c}\text { Percentual } \\
\text { de itens do } \\
\text { ENEM } \\
\mathbf{2 0 1 1}(\boldsymbol{\%})\end{array}$ & $\begin{array}{c}\text { Percentual } \\
\text { total de itens } \\
(\%)\end{array}$ \\
\hline RNF & RND & 10 & 11,1 & 50 & 24,1 \\
\hline RNP & RNF & 30 & 55,5 & 20 & 34,5 \\
\hline RNP & RND & 20 & 44,4 & 30 & 31,0 \\
\hline RND & RNP & 10 & 22,2 & 10 & 13,8 \\
\hline RNF & RF & 0 & 11,1 & 0 & 3,4 \\
\hline RNF & RNP & 0 & 22,2 & 10 & 10,3 \\
\hline
\end{tabular}

Quadro 5 - Percentuais das conversões entre os registros dos números racionais que podem ser mobilizadas nos itens analisados dos ENEM 2009 a 2011

Fonte: (Silva, 2013)

As conversões entre os registros dos números racionais ocorreram apenas num sentido, com exceção de um item do ENEM 2010, em que a conversão pode ser mobilizada nos dois sentidos. A conversão que tem como registro de partida o numérico percentual e como registro de chegada o numérico fracionário está entre aquelas que podem ser mais utilizadas nas resoluções dos itens analisados dos ENEM 2009 (30\%), 2010 (55,5\%) e no total de itens analisados (34,5\%), podendo ser devido ao fato de que nesses ENEM o significado porcentagem foi o mais mobilizado, de acordo com o gráfico 5. No ENEM 2011 esse fato não ocorreu, porque esse exame apresenta uma mudança quanto aos significados mobilizados nos itens, demonstrando uma uniformidade entre os significados, razão, porcentagem e 
probabilidade. Isso pode estar influenciando o maior número de conversões entre o registro numérico fracionário e o decimal, pois o registro numérico fracionário é o que aparece com mais frequência entre os significados, conforme gráfico 9.

As conversões entre outros tipos de registros podem ocorrer nas estratégias de resolução de 48,2\% (14 itens) do total de itens analisados dos ENEM de 2009 a 2011, e estão relacionadas no quadro 6.

\begin{tabular}{|l|l|c|c|c|c|}
\hline $\begin{array}{c}\text { Registro } \\
\text { de } \\
\text { Partida }\end{array}$ & $\begin{array}{c}\text { Registro } \\
\text { de } \\
\text { chegada }\end{array}$ & $\begin{array}{c}\text { Percentual de } \\
\text { Itens do ENEM } \\
\mathbf{2 0 0 9}(\boldsymbol{\%})\end{array}$ & $\begin{array}{c}\text { Percentual de } \\
\text { itens do ENEM } \\
\mathbf{2 0 1 0}(\boldsymbol{\%})\end{array}$ & $\begin{array}{c}\text { Percentual de } \\
\text { itens do ENEM } \\
\mathbf{2 0 1 1}(\boldsymbol{\%})\end{array}$ & $\begin{array}{c}\text { Percentual } \\
\text { total de } \\
\text { itens }(\boldsymbol{\%})\end{array}$ \\
\hline RF & RNI & 10 & 0 & 0 & 3,4 \\
\hline RLM & RD & 10 & 55,5 & 40 & 34,5 \\
\hline RD & RA & 10 & 55,5 & 40 & 34,5 \\
\hline RF & RA & 10 & 0 & 0 & 3,4 \\
\hline RLM & RNI & 0 & 33,3 & 0 & 10,3 \\
\hline
\end{tabular}

Quadro 6 - Percentuais de conversões entre outros tipos de registros que podem ocorrer nas estratégias de resolução dos itens analisados dos ENEM 2009 a 2011

Fonte: (Silva, 2013)

O maior percentual $(34,5 \%)$ de conversões entre outros tipos de registros corresponde àquela cujo registro de partida é a língua natural e o de chegada é o registro em diagrama, como também as que têm como registro de partida o diagrama e o de chegada algébrico. Esse tipo de conversão pode ser mobilizado, em sua maioria, nos itens que envolvem o significado porcentagem, que ocorreu com maior frequência no ENEM 2010, conforme gráfico 5; nas estratégias que utilizam o raciocínio proporcional.

\section{Considerações finais}

Quanto aos significados quociente e número na reta numérica, não identificamos nenhum item que mobilizasse esses significados dos números racionais nas provas dos ENEM, mesmo a reta numérica tendo sido considerada entre os conteúdos 
algébricos/geométricos e a divisibilidade, entre os conteúdos numéricos, dos objetos de conhecimento da matriz de referência para Matemática e suas Tecnologias do novo ENEM.

Entretanto verificamos a presença de itens pertencentes à mesma prova que mobilizaram o mesmo significado (porcentagem) e registros semióticos (incluindo tratamentos e conversões), sendo a maior diferença entre os dois apenas o símbolo \%, que era apresentado no suporte (gráfico) de um item e no outro ele estava ausente. Esses fatos sugerem uma maior reflexão sobre os critérios de escolha dos itens que poderiam incluir, quanto aos itens que abordam o conceito de números racionais, uma maior distribuição entre os seus significados, uma vez que observamos que esses fazem parte da matriz de referência desse exame.

De acordo com Duval (2003), as conversões são transformações que mudam de acordo com os tipos de registros envolvidos. Na nossa pesquisa tivemos como um dos objetivos específicos identificar as conversões que podem ser mobilizadas nas resoluções dos itens que contemplam o conceito de números racionais nos seus diferentes significados e representações. Verificamos que, com exceção de um item no ENEM 2010, em que na resolução do mesmo a conversão poderia ser mobilizada nos dois sentidos, nos demais itens, as conversões entre os registros dos números racionais ocorreram apenas em um sentido. Duval $(2009$, 2011) afirma que saber converter de um registro a outro não implica, necessariamente, em saber realizar a conversão inversa, pois isso requer estruturas cognitivas distintas que nem sempre o sujeito tem desenvolvido.

\section{Referências}

BRASIL, Ministério da Educação e do Desporto. Secretaria de Educação Fundamental. Parâmetros Curriculares Nacionais (1 a a $\mathbf{4}^{\mathbf{a}}$ series): Matemática. Brasília, MEC/SEF, 1997.

CATTO, G. G. Registros de representação e o número racional - Uma abordagem nos livros didáticos. 2000. 152 f. Dissertação (Mestrado em Educação Matemática) - Pontifícia Universidade Católica de São Paulo, São Paulo, 2000.

DUVAL, R. Registros de representação e números racionais. In: MACHADO, S.D.A.(org.). Aprendizagem em matemática: Registros de representação semiótica. Campinas: Papirus, 2003. p.11-33.

DUVAL, R. Semiósis e Pensamento Humano: Registros semióticos e aprendizagens intelectuais. Coleção Contextos da Ciência. Fasc. I. 1.ed. São Paulo: editora Livraria da Física, 2009. 
DUVAL, R. Ver e ensinar a matemática de outra forma: Entrar no modo matemático de pensar: os registros de representações semióticas. 1.ed. São Paulo: PROEM, 2011.

GOMES, R. Q. G. Saberes docentes de professores dos anos iniciais sobre frações. 2010. 112 f. Dissertação (Mestrado em Ensino de Matemática) - Instituto de Matemática, Universidade Federal do Rio de Janeiro, Rio de Janeiro, 2010.

MARANHÃO, M. C. S. A; IGLIORI, S. B. C. Registros de representação e números racionais. In: MACHADO, S. D. A. (Org.). Aprendizagem em matemática: Registros de representação semiótica. Campinas: Papirus, 2003. p. 57-70.

MERLINI, V. L. O conceito de fração em seus diferentes significados: um estudo diagnóstico com alunos de $5^{\mathrm{a}}$ e $6^{\mathrm{a}}$ séries do Ensino Fundamental. 2005. 215 f. Dissertação (Mestrado em Educação Matemática) - Pontifícia Universidade Católica de São Paulo, São Paulo, 2005.

RAMALHO, B. L.; NÚÑEZ, I. B. Fundamentos do ensino-aprendizagem das ciências naturais e da matemática: as provas do ENEM como referência para o Ensino Médio.

In: RAMALHO, B. L. (Org.). Aprendendo com o ENEM - Reflexões para melhor se pensar o ensino e a aprendizagem das ciências naturais e da matemática. Brasília: Liber Livro Editora, 2011. p. 7-15.

ROMANATTO, M. C. Número Racional: Relações necessárias à sua compreensão. 1997. 158 f. Tese (Doutorado em Educação) - Faculdade de Educação, Universidade Estadual de Campinas, Campinas, 1997.

SANTOS, A. O conceito de fração em seus diferentes significados: um estudo diagnóstico junto a professores que atuam no Ensino Fundamental. 2005. 196 f. Dissertação (Mestrado em Educação matemática) - Pontifícia Universidade Católica de São Paulo, São Paulo, 2005.

SILVA, F. A. F. Significados e representações dos números racionais abordados no Exame Nacional do Ensino Médio - ENEM. 2013. 153 f. Dissertação (Mestrado em Ensino das Ciências) Universidade Federal Rural de Pernambuco, Recife, 2013.

TEIXEIRA, A. M. O professor, o ensino de fração e o livro didático: um estudo investigativo. 2008. 194 f. Dissertação (Mestrado Profissional em Educação matemática) - Pontifícia Universidade Católica de São Paulo, São Paulo. 2008.

Submetido em Novembro de 2013. Aprovado em Abril de 2014. 